...y entonces el exiliado descubre, con estupor primero, con dolor después, con cierta ironia más tarde, en el momento mismo en que ha terminado su exilio, que el tiempo no ha pasado impunemente, y que tanto si vuelve como si no vuelve, jamás dejará de ser exiliado. Puede volver, pero una nostalgia y nueva idealización se apoderan de él. Puede quedarse, pero jamás podrá renunciar del pasado que lo trajo aqui y sin el futuro ahora con que soñó tantos años. ${ }^{1}$

Es un exiliado español de la guerra civil quien se expresa de esta manera en sus memorias, pero bien podría ser un israelita en el antiguo testamento, un cubano exiliado del régimen castrista o un refugiado bosnio residente hoy en cualquier país europeo. $Y$ es que aunque ciertos matices derivados de las condiciones de partida de su tierra de origen, de la duración del destierro y de la evolución interna de ese país, mientras el exiliado está fuera, marcan la diferencia entre un exilio y otro, el impacto del destierro en la mente del que se marcha es el mismo. La forma en que se desenvuelve en la tierra que le acoge, los mecanismos de socialización son los mismos y, sin duda, la relación que establece con la tierra de la que partió también lo es; la nostalgia, el sentimiento de ruptura vital, el desarraigo, son comunes . En las páginas que siguen pretendemos reflexionar, a través del estudio de un ejemplo concreto, el del exilio español de 1939, sobre la actitud del exiliado una vez que, desde el punto de vista político, esa condición toca a su fin. Ese momento en que el desterrado ha de enfrentarse a lo que constituye un nuevo problema: la vuelta a su tierra. Los sentimientos que provoca la vuelta

\footnotetext{
* Licenciada en geografía e historia. Profesora de la Universidad de Huelva, España. Autoa de varios artículos sobre los transterrados y España.

1 Adolfo Sánchez Vázquez, Del exilio en México: recuerdos y reflexiones, México, Grijalbo, 990 , p. $37-38$.
} 
son parecidos en cualquiera de los casos. La vuelta es difícil, y esta dificultad es directamente proporcional al tiempo transcurrido y, sobre todo, a los cambios ocurridos en el país de origen mientras el exiliado está fuera. En algunos casos, el retorno es casi imposible y el exiliado termina sintiéndose extraño en su país de origen y en su país de adopción. En cierta medida, el desterrado termina siendo un desarraigado y, si bien para una parte del exilio, el intelectual, fundamentalmente, tiene la sensación de "no pertenencia", puede servir para ampliar su horizonte personal hasta superar la necesidad de formar parte de algún lugar y considerarse "ciudadano del mundo", como muchos de los que protagonizaron el exilio que vamos a analizar; los más no consiguen recuperarse psíquicamente de su destierro. Con el examen de este caso concreto, para cuyo estudio existen numerosas fuentes por tratarse de un exilio de alta calidad intelectual y que tuvo la suerte de, en su mayoría, conseguir una situación socioprofesional media alta en el país de acogida, pretendemos tomar conciencia de uno de los más graves problemas que hoy tiene planteado nuestro planeta: el de los refugiados; un problema económico y político pero también, y sobre todo, un problema humano.

\section{¿Volver a España?}

El caso concreto del que nos vamos a ocupar es el del exilio español de 1939 en México. ${ }^{2}$ La política "remigratoria" de Franco se inició con el decreto de amnistía de 1945. Fueron, sin embargo, muy pocos los que volvieron. Aún existía la esperanza en que al final de la guerra mundial se precipitara la caída del dictador y los republicanos pudiesen volver triunfalmente. Muchos de los menos politizados optaron por volver en estos primeros años. No obstante, no se produjeron retornos desde México, sí desde Francia. Era lógico si tenemos en cuenta que a México llegaron, en su mayoría, aquellos intelectuales y republicanos más politizados, los que corrían peligro en

\footnotetext{
${ }^{2}$ Sobre el exilio español en México, su historia, sus aportaciones a aquel país, su integración en el mismo, pueden consultarse las obras ya clásicas sobre el exilio como son los seis tomos dirigidos por José Luis Abellán, El exilio español de 1939, Barcelona, Taurus, 1976, y los de Javier Rubio, La emigración de la Guerra Civil, 1936-1939, Madrid, San Martín, 1977. Dedicadas por completo al grupo de exiliados que llegaron a México, habría que destacar las obras de Patricia Fagen, Transterrados y ciudadanos, México, FCE, 1975; la de Ascensión de León Portilla, España desde México, vida, testimonio de los transterrados, México, UNAM, 1978, y el libro homenaje al exilio mexicano, El exilio español en México, 1939-1982, México, FCE, 1983.
} 
Francia y para quienes la vuelta era impensable. Por otra parte, a los exiliados poco politizados que llegaron a México, la adaptación al medio les prometía una situación económica muy superior a la que les ofrecía la España de la posguerra.

Habría que esperar a 1954 para que se produjesen los primeros viajes de exiliados "mexicanos" a España. Un decreto del 6 de octubre del mismo año les permitía la entrada y salida del país con pasaporte obtenido en los consulados españoles de los países de residencia, cuya obtención iba acompañada de una investigación de las solicitudes. El carácter mayoritariamenté politizado de los exiliados en este país volvió a reducir el número de solicitudes. Por otra parte, desde las filas del exilio se levantó una amplia campaña contra la vuelta temporal a España. La solicitud de un pasaporte en los consulados franquistas se consideraba en la "colonia" del exiliado un reconocimiento indirecto del régimen.

Un decreto publicado en 1959 intentaba dar un paso adelante en la recuperación del exilio. Éste establecía la edad mínima para considerar exiliados a los que se habían marchado del país con seis años de edad. Se permitía, además, la entrada del exiliado con el pasaporte de su nueva nacionalidad. Se eliminaba el límite de $\mathbf{3 0}$ días de visita y se reducía al mínimo el número de solicitudes de entrada denegadas.

Durante los años sesenta, varias disposiciones fueron poniendo fin al exilio desde el punto de vista jurídico. Un decreto de 1961 daba seis meses para acogerse a la aministía de 1945. En 1965 se decretó un indulto general; se suprimió el registro de penados y se remitieron las penas por delitos no contemplados en el indulto de 1945. Sin embargo, aún debían solicitar un certificado en los consulados para poder regresar y acogerse al indulto. Finalmente, el 31 de marzo de 1969 se declararon prescritos todos los delitos de la guerra civil. Paralelamente, se eliminó lo que se consideraba por parte del exilio un requisito denigrante: la necesidad de pedir en los consulados el permiso para volver.

La posibilidad de la vuelta temporal o definitiva dependía de varios factores. En primer lugar, del grado de politización del exiliado. Para el exiliado comprometido, mientras Franco estuviese vivo lo estaría también la guerra civil y eso le impedía volver, ya que hacerlo suponía reconocer la derrota. Dependía, en segundo lugar, del país de asilo. La vuelta desde México era más difícil que desde Francia, por menos necesaria. La política de naturalizaciones, adoptada desde 1940 por el presidente Ávila Camacho, había dado buenos resultados: entre un 70 y 80 por ciento de los exiliados adopta- 
ron la nacionalidad mexicana. La integración había sido más fácil que en Francia, por afinidad cultural, aunque también es cierto que la distancia la había hecho más necesaria. Por otra parte, la situación económica de los exiliados en México era mejor que la de los residentes en Francia y la que podrían tener en España. Además, los viajes temporales eran más costosos desde América que desde el país vecino. Todo ello hacía la vuelta definitiva menos necesaria y la temporal más complicada que desde Francia. La posibilidad de la vuelta temporal y la cercanía física hicieron que la reintegración desde el exilio francés a la vida española de la transición fuese más fácil que la del exilio mexicano, y, por las mismas causas, más idealista y más alejada de la realidad española que el francés.

El regreso era, ante todo, una decisión política, que el refugiado convertía en una cuestión de dignidad. Atendiendo a su postura ante la vuelta, podríamos dividir el exilio mexicano en tres grupos:

a) Los que trabajaban activamente para volver y reintegrarse a España hasta la muerte. Mantienen vivas las ideas de exilio y se sienten doloridos por el olvido del que son víctimas por parte de la España de la transición.

b) Aquellos que, ante la imposibilidad mental de la vuelta, convierten su exilio en definitivo. Este grupo lo integran aquellos que llegan a aceptar la doble patria de José Gaos; los que superan la idea de pertenencia a un lugar y llegan a considerarse ciudadanos del mundo, hecho que observamos sobre todo entre los exiliados anarquistas; y los que llegan a asumir el exilio hasta el punto de afirmar que nacieron exiliados, porque su país es una España ideal, que nunca tendrá una expresión real.

c) El tercer grupo lo forman aquellos que deciden rehacer su vida y superar la angustia del exilio, integrándose plenamente en la vida de México, sin romper con España por cuanto su origen les garantiza un estado social determinado. Son acusados por sus compañeros de haber traicionado la causa y haberse "gachupinizado", ${ }^{3}$ pasando de su condición de exiliados a la de emigrantes económicos.

\footnotetext{
${ }^{3}$ El concepto de gachupín, utilizado por los mexicanos desde la Revolución para referirse a los españoles, y por los refugiados para referirse a la colonia de emigrantes económicos, establece una distancia social y culțural insalvable entre México y la colonia española. El gachupín, en lo social, recuerda a los mexicanos a los administradores de las haciendas de la época del Porfiriato, apegados al trabajo y más duros con los peones que el amo. A esa imagen de capataz, puesto que ocuparon tradicionalmente esos emigrantes españoles a su llegada a México, se une otra connotación negativa, como cazadores de dotes de familias criollas ricas que deseaban casar a sus hijas con españoles. Desde lo cultural, el mexicano culto considera gachupín al español que hizo fortuna en su país, pero que, falto de educación, se comporta como un nuevo rico.
} 
Según Javier Rubio, entre 1945 y 1969, sólo un 15 por ciento del exilio masculino pidió permiso para volver desde México. Por otra parte, Patricia Fagen señala que, cuando fue posible retornar, sólo un 10 por ciento de los exiliados en México deseaba hacerlo de forma definitiva. Sí existía, sin embargo, un mayor porcentaje que deseaba viajar para visitar a sus familiares y para romper de una vez por todas con el sentimiento de nostalgia que minaba sus vidas. Un dato más de la autora: eran bastante más frecuentes las visitas a España de las mujeres del exilio que de los hombres. No hay que olvidar que la gran mayoría de españolas que fueron al exilio lo hicieron más por acompañar a sus parejas que por motivos políticos; no existía pues para ellas razón ideológica para negarse a volver mientras Franco estuviese vivo. ${ }^{4} \mathrm{Y}$, sin embargo, después de todo, la visita a España no parecía servir para mitigar la nostalgia sino todo lo contrario, por cuanto era nostalgia no de un lugar, sino, sobre todo, de unos años de juventud y de un ideal que ya no existía.

En 1981, el Instituto de Investigaciones Antropológicas de la Universidad Nacional Autónoma de México realizó un estudio sobre el exilio español, basándose en 120 entrevistas realizadas a figuras prominentes del mismo, de diferente signo político y generación. De ellas, 45 habían vuelto a España, unas pocas muy politizadas que se quisieron subir al carro de la transición. Algunos, muy mayores, volvieron a morir en casa, a completar el círculo y es que, parafraseando a León Felipe, no había nada peor que morir en tierra extraña porque era un morir que precedía al nacer, que lo anulaba. Otros se habituaron a hacerlo periódicamente; ello les permitió enfrentarse al problema de la nostalgia y continuar con la vida rehecha en México. Unos pocos ni habían vuelto ni lo harían, pues se sentían agraviados por una transición que no había sido más que el triunfo del posfranquismo. Finalmente, hubo quienes volvieron con la intención de quedarse, pero ante la realidad de un país que los había olvidado y en el que no tenían lugar, decidieron exiliarse de nuevo, iniciando así su segundo exilio y tomando conciencia de que el suyo era un exilio sin fin. ${ }^{5}$

\footnotetext{
${ }^{4}$ Sobre el pensamiento y actitudes de esa mayoría de mujeres que fueron al exilia despolitizadas, es muy interesante el análisis que, partiendo de las entrevistas realizadas por el archivo oral del exilio del Instituto de Investigaciones Antropológicas de la UNAM, hace Pilar Domínguez Prats en Voces del exilio: mujeres españolas en México, 1939-1950, Madrid, Dirección General de la Mujer de la Comunidad de Madrid, 1994.

${ }^{5} \mathrm{El}$ archivo oral, resultado de esta investigación, es fundamental para conocer las actitudes de los exiliados al volver y su imagen de la España de la transición. Está compuesto de unas grabaciones realizadas en México y España, de propiedad del Estado mexicano y de las que existe una copia transcrita en Salamanca. Por otra parte, no hay razón para pensar que desde
} 
Existía un factor añadido que impedía la vuelta temporal a España: la censura a que eran sometidos los que volvían por parte de sus compañeros en el exilio. Los primeros en volver a España temporalmente, entre 1945 a 1954, fueron los denominados "refugiados de tropa"; esas visitas no preocuparon a los sectores politizados del exilio. La irritación se dio cuando, entre 1954 y 1969, perdida la esperanza en la caída de Franco, los viajes comenzaron a generalizarse. Algunos miembros eminentes del exilio volvieron a España para integrarse en una lucha política que, ya estaban seguros, sólo debía realizarse desde dentro. Desde las publicaciones del exilio, se embistió duramente contra aquellos que volvieron. ${ }^{6}$ Para el exilio que se negó a volver, incluso temporalmente, la vuelta significaba dar la razón a Franco, aceptar con humillación la justicia franquista y reconocer que eran los culpables. Sólo existía la derrota cuando el vencido la aceptaba, pregonaban, y volver era reconocerla.

Entre 1969 y 1975 , conforme el exilio fue desapareciendo desde lo jurídico, los sectores más politizados se fueron quedando solos. Ese abandono aumentó su irreductibilidad. Conscientes de haber perdido toda influencia política en el interior de España y convencidos de ser los últimos idealistas, los depositarios de la causa del exilio asumieron una tarea testimonial que se resume en una frase: "iEl exilio no se rinde! Ellos eran los últimos representantes de la santa intransigencia republicana." Purificación Tomás, una de las

Francia se produjesen más retornos definitivos que desde México, aunque sí eran más frecuentes los viajes temporales y menor esa sensación de sentirse fuera, que el exilio mexicano tiene cuando viene a España. Nancy MacDonald, en Homage to the Spanish Exilus, New York, Insight Books, 1987, p. 335, señala que entre las 664 entrevistas realizadas a exiliados en Francia, en 1978, sólo ocho estaban decididos a volver de forma definitiva. Con respecto a la vuelta, los exiliados vascos en México constituyen una excepción. Sus viajes temporales, en vida del dictador, fueron bastante más frecuentes que los del resto del exilio. Y es que, si los exiliados para volver necesitaban superar la barrera que suponían las críticas de deserción por parte de sus compañeros, la situación de resistencia generalizada del pueblo vasco en la península, "ocupado por Franco", hacía que volver al País Vasco no fuese una aceptación indirecta del franquismo y por tanto una deserción.

${ }^{6}$ Hasta tal punto llega el miedo a desaparecer, que el exilio se obsesiona en los 70, cuando es más débil, en evitar los viajes a España y cualquier contacto con la España franquista. Ello produjo numerosos incidentes. Javier Rubio recoge la expulsión del Centro Republicano Español de un grupo de miembros que asistió a una comida organizada en honor de Martínez de la Mata, representante no oficial del gobierno de Franco en México, con el que tenían contactos personales, por considerarlo una traición. Una ojeada a las revistas del exilio nos da una idea de la imagen negativa que se fomenta hacia aquellos que vuelven. En la revista Mujer, en su número de enero de 1976 , se critica con ironía a aquellas mujeres exiliadas que en sus tertulias de mercado han pasado de cuantificar el tiempo que faltaba para la caída de Franco, a chismorrear incansable y frfvolamente de la vuelta a España. Los abanderados de esa batalla contra la vuelta son los Boletines del Centro Republicano Español en México.

${ }^{7}$ Fernando Serrano Migallón, "La República española en el exilio", Catálogo de la exposición El exilio español en México, Madrid, Ministerio de Cultura, 1983-1984, p. 29. 
pocas exiliadas que finalmente volvió a incorporarse en la política, se expresaba así sobre la postura del exilio en 1971:

Pensamos que permanecer en el exilio es una postura digna. Hemos envejecido, estamos lejos de la realidad española, pero Franco sigue en España simbolizando todo aquello que nos hizo salir de ella, como nosotros estamos fuera como exponentes del espíritu antifranquista. Muchos han muerto, probablemente se nos tache de quijotescos con visos de locos y soñadores, pero don Quijote ha sido y seguirá siendo un símbolo de la forma de ser española. ${ }^{8}$

Volver representaba, además, una serie de dificultades más pragmáticas. Tras tantos años de exilio, era bastante difícil crearse una nueva vida personal y profesional en España. El regreso no les podía garantizar una situación social, profesional y económica parecida a la que en esos momentos gozaban en México. Los que más deseos tenían de volver eran los menos integrados en este país, los que habían dedicado su vida a la política. Para estos hombres, el exilio fue más duro que para el resto, porque si un maestro podía ejercer como tal en el país de acogida, un político al exiliarse perdía no sólo su tierra sino también su profesión. Regresar para ellos era continuar su carrera política, refrendar su compromiso con España, $y$, en cierta medida, volver a existir plenamente. Sin embargo, siendo ellos los que más ansiaban el regreso, son ellos los que se negaban a regresar y los que cuando lo hicieron recibieron la más honda decepción. Por ser precisamente los más politizados, estaban decididos a no volver hasta que en la península se les permitiese participar en la vida pública. "Permanecemos en el destierro no por vanidad ni maldad, sino porque la patria sigue sin ofrecernos las condiciones mínimas seguras y honorables de habitabilidad." Cuando volver a participar fue posible, el exiliado se dio cuenta de que el retorno era imposible. La vuelta, tan deseada, perdía entonces su sentido. Regresar no era volver a vegetar, sino a trabajar en la construcción de esa nueva España y ellos no estaban en condiciones físicas de hacerlo, ni eran aceptados por la España interior.

Hasta la muerte de Franco, los partidarios de la no vuelta tenían una justificación que perdieron con la muerte de éste y el desarrollo de la transición. Muerto el caudillo, el exilio, que jurídicamente había desaparecido, se desvaneció. No obstante, una parte de él, ésa

\footnotetext{
${ }^{8}$ Purificación Tomás, "El exilio es tristeza y una dura prueba para la dignidad", Mujer mayo, 1971, p. 1.

${ }^{9}$ Argentina Martín, "Viaje a España”, Horizontes, mayo, 1977, p. 3.
} 
que estaba adscrita a ARDE, para quienes la única solución viable para España era la república, continuó afirmando su intransigencia. Lo hacía justificándose en que España le había negado la participación en la transición al vetar su presencia en las elecciones de junio de 1977. Fernando Valera, principal representante de ese grupo, reafirmaba así su irreductibilidad en 1976: "Llevo 79 años cumpliendo con mi deber, y aquí estaré hasta que se haya producido el acto histórico que me licencie [...] volver es volver para luchar", y hasta que no se les permitiese hacerlo no volverían. ${ }^{10}$ Cuando la España del futuro - esa que se llevaron 40 años imaginando desde la tribuna del exilio- se hizo realidad, muy pocos de ellos se decidieron a volver para participar en ella. Los que lo hicieron pronto se dieron cuenta de que ese futuro soñado no tenía nada en común con la forma que tomó la España posfranquista.

Esa vuelta en el sentido de participación, condición indispensable para volver, factible en el caso socialista, comunista y anarquista, se hizo mucho más difícil para los republicanos, a quienes el proceso de la transición no pudo o no quiso aceptar. En 1977, ARDE - surgida en 1960 de la unión de los antiguos partidos republicanos-decidió solicitar su inclusión en el registro de partidos. Intentando superar la decepción que supuso la evolución de España, muerto Franco, aceptaron la transición como un proceso coyuntural. Sólo había que esperar, prolongando la labor testimonial en que se habían empeñado: "un millón de muertos y cuarenta años no fueron suficientes, pero tenemos que volver porque ha llegado el momento de participar políticamente y fuera nos falta autoridad moral para hacerlo"." Sin embargo, el registro les fue negado. Fuera de la transición hasta después de las elecciones de 1977, los republicanos, a través de República Española y de los boletines del Centro Republicano Español, denunciaron continua y escrupulosamente la ilegitimidad monárquica; conservaron la esperanza en la Tercera República como única forma que garantizaría la democracia en España; criticaron el ostracismo a que se había castigado a las fuerzas republicanas. Con obstinación, unos pocos republicanos (Fernando Valera, Francisco Varea, Mariano Joven) se empeñaron en la necesidad de continuar y de mantener la dignidad durante un proceso que, al no permitirles su participación, reconocía que les tenía miedo y que, en cierta forma, su actitud era legítima. ${ }^{12}$

\footnotetext{
${ }^{10}$ Fernando Valera, en República Española, 15 de marzo de 1976, p. 34.

${ }_{11}^{1}$ José Luis Peñalva, en República Española, 15 de julio de 1976, p. 5.

12 Esa digna intransigencia que se mantiene queda expresada así por Manuel Vega en Boletín del CRE. núm. 15. 15 de abril de 1978. n. 5 :
} 
Al margen de ese pequeño grupo aún activo, para el cual la muerte de Franco no significó el fin del exilio, ćregresó el exilio cuando ya había desaparecido el sujeto de su desdicha? No. Muerto el dictador, las razones para no volver fueron de índole diversa, desde las humanas, que suponían haber creado una familia en este país, a las profesionales y económicas. Empezar en España desde cero y con su familia en México era imposible. A todo ello se unió un hecho esencial: su España, aquella en la que soñaron tantos años regresar, no era una realidad, era un sentimiento y un sueño, al que no se podía volver porque no existía.

España al volver, la realidad frente al sueño

España es la mía, la de mis sueños, la de mis años niños, lejana [...] una puerta que se abre a la vida y yo empiezo a sentir. me persona y sueño, y canto y río y lloro y veo la muerte cerca [...] yo quiero a Espana por lo que nunca tuve pero pude sonar. ${ }^{13}$

La vuelta, si se produce, supone un doble choque. En primer lugar con una realidad que no es, que no puede ser la soñada en la mente de cada uno; que no es siquiera la recordada, sino la idealización de esos recuerdos, unidos para muchos a la natural añoranza de los años jóvenes cuando la muerte se acerca. Para otros, que llegaron niños o nacieron allí, no quedan ese tipo de recuerdos, sino los aprendidos de los recuerdos de sus padres, con lo que la idealización es mayor. Unos y otros convirtieron a España en un paraíso perdido, una utopía. Cuando se enfrentan a la realidad muchos de ellos no pueden aceptarla, prefieren volver la espalda para continuar viviendo en su exilio.

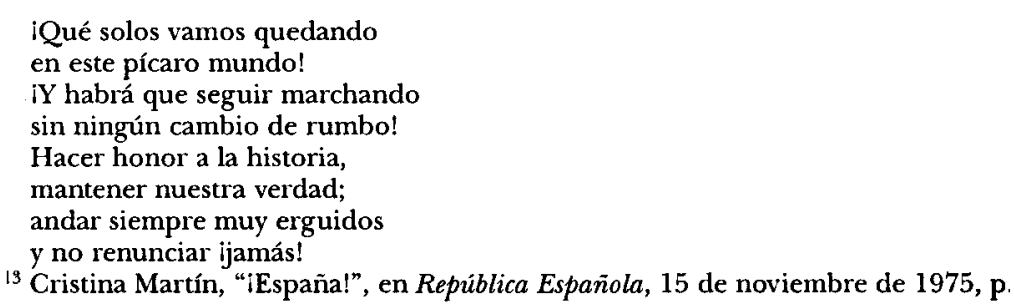


Todavía a la vuelta, España les tiene preparado un segundo choque, que analizaremos en el próximo apartado, y que los convierte en fantasmas, en el objeto de la desmemoria que preside la historia reciente de nuestro país.

El exiliado percibe a su llegada un desacompasamiento entre su imagen de España y la realidad. Desde el punto de vista físico, político, económico y mental, la España que se encuentra ha evolucionado en una forma y a una rapidez tal que la convierten en una desconocida; sobre todo para quienes la imagen de España se congeló a su salida, en los años treinta. ${ }^{14}$ Los exiliados, que volvieron hasta la mitad de los años cincuenta, desde el territorio francés, sobre todo, tuvieron la oportunidad de reintegrarse, con mayor o menor éxito, a la sociedad española. Desde entonces, la evolución del país se aceleró y un extrañamiento creciente impidió la reintegración.

La sorpresa, la rareza y la desorientación que implicaba la vuelta no eran ni algo nuevo ni algo privativo del exilio español de 1939. Vicente Lloréns ${ }^{15}$ encontró en las memorias de Alcalá Galiano los mismos sentimientos que encontramos en los hombres de 1939 al volver a España. Sin embargo, sí hubo algo que hizo único en la historia de España al exilio de $1939 .{ }^{16}$ La imposibilidad de reintegración fue bastante más grave por dos causas: por el tiempo que duró este exilio y, sobre todo, por el acelerado proceso de cambio que España vivió

\footnotetext{
${ }^{14}$ Hay que señalar que, desde el exilio, el viaje a España tiene una utilidad política. Aquellos que vuelven se empeñarán a la vuelta a México en transmitir una imagen negativa de España que aliente a sus compañeros en la permanencia del exilio y que los persuada para no volver. Entre las numerosas impresiones de sus viajes a España, que encontramos en las revistas del exilio, sólo Fidel Miró reconoce algunos cambios positivos en España. Confirma que viaja a España con la intención de cotejar algunas de sus opiniones ideológicas con la realidad española y concluye su viaje afirmando, contra sus compañeros de exilio: "La Espana actual no es, ni mucho menos, lo que la gente tiene en mente... Correspondian a viejos clichés del exilio que no ref lejan la realidad política, social y económica que constituye la vida del país", en Comunidad Ibérica, op. cit., p. 33.

${ }^{15}$ Vicente Lloréns, Liberales románticos, op. cit., p. 424. El mismo extrañamiento y las mismas dificultades para reintegrarse que se dan en el exilio del 39 aparecen en una carta de Alcalá Galiano al Duque de Rivas, recogida por éste en el primer tomo de sus memorias. El liberal se expresa así:

"donde aplausos dejé miro despego,

donde amistad tibieza,

un yermo de ceniza donde fuego,

vejez donde belleza.

No es ésta no mi España suspirada

la que adoré constante,

la imagen halagüeña que invocada

tuve siempre delante."

${ }^{16}$ Si nos preguntásemos, en un país de exilios como es España, por el más parecido al de nuestra guerra civil, quizás nos llevaríamos una sorpresa al encontrar que, al menos en el tema de la imagen que España tiene en el exilio, aquel que expresa sentimientos más parecidos al que analizamos es el exilio sefardí. Uno v otro fueron exilios sin fin en la historia de Esnaña.
} 
en los años sesenta. Al exiliado que volvió le resultó extraña la evolución política, económica y mental de su país; eso se tradujo en una profunda sensación de desarraigo, que lo apartó de esa nueva España y que desencadenó la vuelta al exilio vital, un retorno hacia sí mismos y hacia "su España" para vivir en una especie de bola de cristal:

La vuelta imposible se ha convertido en adorable. Muchos han regresado ya $[. .$.$] y vuelto. Y ¿qué pasa? El retroceso aterrorizado, encontrar que$ después de todo no se está tan mal aquí [...] En fin, en el fondo existe una verdad, el temor de que el país soñado, tan remodelado por la imaginación y la nostalgia, se convierta en cenizas al palparlo. ${ }^{17}$

El exiliado no encontraría, no podía hacerlo, la España que buscaba porque ésta no existía más que en su imaginación. Se había producido un desacompasamiento entre la España real y la del exiliado, la de los años treinta revivida, rememorada, soñada, que conserva intactos los prejuicios de la España de la guerra, un paraíso mental, una utopía en la que aquél puso sus esperanzas durante los duros años del exilio.

Extrañeza, a veces estupor, produjo en el exilio la evolución económica, social y mental de la península, pero quizás el aspecto más inesperado- y para la mayoría decepcionante- con que el exilio se enfrentó fue la evolución política. El proceso político que se inició tras la muerte del caudillo fue, para los más indulgentes, un mal menor. La transición fue un hecho consumado por unos seres desconocidos: los españoles del interior; un proceso que transigía con todos los ideales defendidos en el destierro, convirtiendo así el sacrificio, que ellos se consolaron pensando que hacían por España, en papel mojado. Fue sin duda el inquietante "chaquetismo", el pragmatismo, la ausencia de maximalismo, instituidos por la transición, lo que fomentó la imagen negativa de la misma entre los exiliados. Se había llegado a tal punto, escribían, que ésa sería llamada la época del "fregolismo" (famoso transformista español de principios de siglo). Con añoranza recordaban los "ifelices tiempos en que aún existían ideologías por las que luchar toda la vida!", y no ese consenso que se asemejaba mucho a la complicidad. Los hechos les habían dado la razón a todos aquelos que desde México dudaron de la autenticidad de los representantes de sus partidos en el interior. ${ }^{18} \mathrm{El}$ líder socialista histórico Miguel Peydró llegó a afirmar, con ironía y con dolor, en 1979:

17 Testimonio de Sara García Iglesias recogido por P. Fagen, op. cit., p. 198.

18 Pozuelo, "No crea en usted ni en los demás", en Boletín del CRE, núm. 23, diciembre de 1978 , p. 6. 
La República no murió el 18 de julio, ni el uno de abril de 1939, sino el 15 de junio de 1977, cuando llegaron al Congreso cerca de ciento cincuenta diputados supuestamente republicanos porque pertenecían a partidos que siempre lo fueron, y no pronunciaron ni una sola palabra, ni hicieron gesto alguno en su recuerdo. ${ }^{19}$

Si desde lo político al exilio le resultaba difícil asimilar los cambios en España, no fue menor el proceso de extrañamiento con respecto a sus compatriotas desde lo mental. Los españoles estaban dominados por el consumismo, por la desgana y por la pérdida de los valores -se quejaban los exiliados. En España había triunfado la sociedad de consumo y era esa sociedad la que había degenerado en una "política de consumo". Los peninsulares trabajaban poco y mal, gastaban por gastar, continuaban viviendo una de esas cíclicas etapas históricas en que era más Sancho que Quijote, volvían a estar dormidos mientras un pequeño grupo dirigía el proceso a su antojo. Absurdamente -señalaban desde el exilio-, se había convertido en la máxima aspiración de los españoles obtener "un empleo seguro a cambio de nada [...] en una administración burocratizada e ineficaz, con un absentismo escandaloso" ${ }^{20}$ Los iberos, además, habían "perdido los valores morales y espirituales, lo que unido al destape sexual producía un materialismo exacerbado y un consumismo insatisfecho que desembocaba en una neurosis colectiva". Y, para colmo de males, habían olvidado lo que los exiliados consideraban grandes valores: el "respeto a la familia y a la vejez". ${ }^{21}$

Ya nada era igual en España, decían los exiliados. Tan era así que recordaban con nostalgia cómo en la España de antes todo tenía "más sabor", era más auténtico; iincluso la comida! ${ }^{22}$ Daba la impre-

\footnotetext{
${ }^{19}$ Miguel Peydró, "En recuerdo de la República", en Boletín del CRE, núm. 28, mayo de 1979 , p. 6.

${ }^{20}$ Antonio Márquez, "La francachela sigue", en Boletín del CRE, núm. 19, agosto de 1978, p. 2.

${ }^{21} \mathrm{~J}$. Alonso Giner, "¿Qué les pasa a los españoles?”, en Boletín del CRE, noviembre de 1980, p. 4.

${ }_{22}$ A. Casals publica, bajo el titulo de "La ensalada", un sugerente artículo en el Boletín del CRE, núm. 32, septiembre de 1979 , p. 5. En él se queja de una España en la que todo es light. Ni siquiera la lechuga es ya lechuga, las ensaladas de la República sabían a eso, a ensaladas, hoy en España hasta la ensalada ha perdido su sabor natural, para convertirse en algo artificial e insípido; como la transición. En este sentido nos atreveríamos a señalar que quizás la extrañeza y disgusto que provoca la transición en el exilio es un sentimiento compartido por los supervivientes de la otra Espana. Las críticas que se hacen desde el exilio al proceso de transición no nos parecen muy diferentes de las que hacen sus enemigos. Aunque desde diferentes ideologías, la imagen negativa de la transición la comparten ambos. En este caso sería cierto que la transición fue la eclosión de una España nueva frente a las otras dos, que perecieron ambas, en una guerra que terminó con la muerte de Franco. Esas dos Españas han quedado en el pasado, y unos y otros son sólo supervivientes, sin un lugar en esa España nueva.
} 
sión que en la República todo era más puro, más violento, más primitivo; pero con mayor personalidad y grandeza. La derecha era la derecha y la izquierda izquierda, no había atenuantes. La Iglesia seguía una ortodoxia y era defensora de una moral estricta; lo que se esperaba de ella. Los refugiados no podían entender el consenso político y moral de la transición porque, a su edad, eso suponía romper con el esquema mental que tenían formado sobre España. Un esquema que se fincaba en los años treinta, sin evolución alguna, por la falta de contacto directo con la península.

La transición española fue un sainete o un teatro del absurdo para los exiliados que la vivieron desde México. ¿Era posible en ese ambiente una reconciliación de la transición política con los exiliados que permanecían en el exilio? Los refugiados pusieron sus condiciones morales y materiales para la reconciliación:

a) El restablecimiento de todos los nombramientos oficiales realizados por el gobierno republicano hasta el final de la guerra, con la categoría que debieron haber tenido de continuar en activo y con las jubilaciones pertinentes.

b) Pensiones para las viudas e hijos de los muertos durante la guerra.

c) La restitución de los bienes expoliados a personas y sociedades por los nacionales.

d) Igual tratamiento moral y material a los mutilados de la zona republicana que al brindado a los de la zona nacional.

e) La rehabilitación moral de los caídos por la República, cuyo acto simbólico podría ser la creación de monumentos en toda España que, de la misma forma que las cruces de los caídos, los recordasen. ${ }^{23}$

Ciertamente, conforme fue avanzando la transición política, la reconciliación fue estando más cerca. Desde el punto de vista político la jalonaron: la amnistía general dictada el 11 de marzo de 1977; la legalización de $A R D E$ en agosto de 1977; el reconocimiento de las pensiones, cuyos primeros pasos se dieron el 7 de abril de 1976 y que sólo tras los decretos de 1981 fueron consideradas justas por los exiliados; y, finalmente, el triunfo del Partido Socialista Obrero Español. ${ }^{24}$ Sin embargo, el exilio siguió pensando que la socie-

\footnotetext{
${ }^{23}$ P. M., "Monarquía, República, reconciliación", en Boletín del CRE, núm. 20, septiembre de 1978 , p. 5.

${ }^{24} \mathrm{El}$ exilio quedó sorprendido gratamente por el triunfo del PSOE, que fue recibido como un éxito del exilio. Pero ante todo vino a demostrar algo: que en verdad no conocía a la España nueva, pues en su imagen de España hubiese sido improbable una victoria tan limpia y paćfica como aquélla. El exiliado recobró la confianza en que un gobierno socialista compensase moralmente al exilio y abriese, aunque ellos ya no lo viesen, el camino a la Tercera República. Así se recibió la llegada de los socialistas en el Centro Republicano Español:
} 
dad española tenía una deuda moral con él; y es que la reconciliación que deseaba debía hacerse sobre la base de una aceptación de lo que fueron las dos Españas y no en el olvido de ambas.

\section{La legión de los olyidados}

As to my return to Spain, at my age, seventy-five, Spain has lost the attractions it had in my youth [...] If fear I will be condemned to die without seeing it, like so many others among us who form the enormous legion of the forgotten. ${ }^{25}$

No fue sólo extrañeza lo que sintió el exiliado de vuelta a España; existió otro proceso al que se hubo de enfrentar el exilio: el olvido del que fue objeto por parte de los nuevos españoles. La reconciliación, base de la transición, necesitó hacer tabla rasa del pasado, olvidarlo intencionadamente para concentrarse en el futuro. Los exiliados, consecuencia directa de una guerra que quedó sepultada en la memoria, pagaron con ese olvido el precio de una transición pacífica.

Los resultados de la vuelta fueron en todo caso negativos. El exilio tomó conciencia del doloroso fracaso de sus 40 años de actividad, cuando tuvo que asimilar que para los españoles no existía, no era más que historia enterrada.

En el terreno político, el exiliado se enfrentó dentro de su propio partido a su sustitución por los jóvenes, a quienes hubo de dejar el protagonismo para quedarse en una posición simbólica. Pronto se dio cuenta de que el fracaso no era sólo personal sino ideológico. La evolución ideológica del interior estaba bastante alejada de la ortodoxia defendida desde el exilio. Pero no fue sólo ese fracaso político el que percibió el exiliado al volver. A la conciencia de su

\footnotetext{
"iQué país!, ibamos envejeciendo en el tedio, desesperanzados [...] cuando de repente la España de Cervantes nos hace la respiración boca a boca y nos resucita [...] España decide reescribir la historia, osadamente y con el coraje prepotente español, el valor del Cid, retorna la maldita historia y la reescribe, pisando fuerte y como hombre. España es hombre." María Luisa Mendoza, "España, hombre que preña", en Boletín del CRE, núm. 72, noviembre de 1982 , p. 5.

${ }^{25}$ Palabras dirigidas por el exiliado M. Martín a Nancy MacDonald, y recogidas por ésta en Homage to the Spanish Exiles, New York, Instinght Books, 1987, p. 15-16. El título de este apartado responde a la expresión que la misma autora utiliza en su libro para referirse a la situación del exilio de 1939 con respecto a la España actual.
} 
prescindibilidad en la vida política de la España nueva, se sumó un fracaso, aún más doloroso, en el terreno moral y testimonial. Fue ésa la derrota última del exilio, por cuanto el valor testimonial y ejemplificador era ya, tras fracasar en lo político, lo único que le quedaba, lo único que daba sentido a sus vidas y a su sacrificio. Aquellos refugiados que retornaron percibieron cómo la nueva sociedad española no quería hablar de la guerra civil, no los conocían, ni les interesaba hacerlo. ¿Qué sentido sostenía pues al exilio si había fracasado en el terreno político y testimonial? Ninguno.

Esa sensación de fracaso derivó en un profundo complejo de olvido. Unos tomaron conciencia de la imposibilidad de la vuelta y se encerraron en su exilio permanente; los menos intentaron luchar contra el fracaso, contra el olvido, reivindicando hasta su muerte el reconocimiento del exilio por parte de la España de la transición.

Max Aub, en la obra titulada Las vueltas, reflejó extraordinariamente el choque del regreso y las reacciones que ese duro encontronazo desencadenó. Al desacompasamiento que el exiliado sintió a su llegada, se unió una profunda decepción por la forma en que la España interior reaccionó a su regreso: de una parte, el acusado resentimiento de "los que se quedaron"; de la otra, el olvido, consciente o inconsciente, de los nuevos españoles. Los unos y los otros terminaron por expulsar al exiliado que había retornado, negándole su pertenencia a esa nueva España, su derecho a participar en ella. El refugiado no pudo integrarse porque ésta no era su España, pero también, según Max Aub, porque España no le dejó hacerlo.

Merece la pena comentar la obra a la que aludimos. El protagonista era un exiliado que volvía, al final de su vida, en busca de sus recuerdos, ${ }^{26}$ a recuperar no sólo España sino, sobre todo, su juventud $^{27}$ y lo hacía con orgullo y con dignidad, esperando recuperar a España donde la dejó. Sin embargo, su reencuentro con sus compatriotas fue muy distinto al soñado. Sentado en un lugar tan hispano como un café, el exiliado vio pasar por delante una galería de personajes de la España interior, cada uno de los cuales reaccionó de diferente manera a ese reencuentro. Quizás los que lo hicieron más duramente fueron "los que se quedaron", sus antiguos compañeros

\footnotetext{
26 "Mientras uno vive sin pensar en el fin, señala el protagonista, lo hace en cualquier lugar. Cuando en el horizonte aparece la meta, el nicho, uno, aunque no le importe la muerte, piensa en redondear la faena, en entrar a matar o morir." Max Aub, Las vueltas, México, Mortiz, 1965, p. 60.

${ }^{27}$ Vuelve cuando la muerte está cerca a recuperar España, a recuperar su juventud, su antigua novia, sus antiguos paisajes, a recuperar en parte la guerra que mira con nostalgia, pues en ella convivieron lo peor y lo mejor de cada ser humano. "Vuelvo para sacarle jugo a la vida en el momento en que ésta se agota." Ibidem, p. 74.
} 
en la batalla y su vieja novia. ${ }^{28}$ No lo recibieron con los brazos abiertos, sino con cierto resentimiento. Sus antiguos camaradas le reprocharon la incomprensión del exilio con la, a veces inevitable, transigencia del interior. Éstos les negaban el derecho de crítica a quienes, al fin y al cabo, la vida en México les había proporcionado una seguridad económica y una tranquilidad que ellos, dentro de España, nunca tuvieron. Si querían hacer algo en la España nueva, que no pensasen que se les iba a tratar con honores, habrían de empezar desde cero. ${ }^{29}$

Tras el decepcionante encontronazo con sus correligionarios, el refugiado conversó con dos grupos de jóvenes; uno representaba a la juventud franquista; el otro a la de la oposición. Los primeros le preguntaron a qué había vuelto cuando todo estaba solucionado. Para el protagonista, esta juventud hispana tenía como única ambición el divertirse; eran pragmáticos y felices, con "una felicidad que no venía de la libertad sino del consumo"; no conocían los nombres de los grandes políticos del exilio; no sabían nada de la guerra civil y no les interesaba; estaban convencidos de que en España se vivía mejor que en el resto del mundo. Sin embargo, de la misma manera que vio pasar, desde su tribuna en el café, más proclive siempre a la discusión que a la acción, a la juventud despolitizada, el exiliado encontró un pequeño grupo de universitarios que lo reconocieron y expresaron su deseo de ser instruidos por él. No obstante, ese reencuentro no fue más positivo que el anterior. Se dio cuenta de que ni siquiera ese pequeño grupo activo conocía su obra y las ideas que constituían su esencia como hombre. Por otra parte, el hecho de ser considerado maestro le confirmaba que, para esa nueva oposición, su historia activa estaba acabada, lo que no dejaba de ser doloroso.

\footnotetext{
${ }^{28}$ Es precisamente esa vieja novia, con quien pretende restablecer relaciones, quien, con amargura e ironía, critica la postura del exilio exterior desde el punto de vista de los que se quedaron: “iCómo han debido cambiar vuestras ideas sobre el regreso! En 1945, arrebató a fondo, sobre caballos blancos, cargando, no dejando hueso sano al enemigo; en 1948, dispuestos al diálogo, al perdón, la mano tendida, generosos. En 1950, de igual a igual, y, desde entonces, cada vez más pequeños, hasta tocar a la puerta" (p. 57). El resentimiento es patente cuando ella misma afirma, ante las quejas del exiliado: “ Desterrados no lo erais vosotros; desterrados nosotros. Fueron años desesperados, sin más salida que los muros, aunque tuviésemos los huesos cargados de esperanza"; mientras ellos fuera no se acordaron de los de dentro (p. 64). Los acusan, finalmente, de explotar el exilio: en el caso de los escritores, es común ocupar un puesto más alto en la valoración pública, más por el hecho de ser exiliado, que por la categoría de su obra. Ibidem, p. 101.

${ }_{29} \mathrm{Si}$ de verdad quieren volver, lo han de hacer sin orgullo, conscientes de que no son indispensables, "tenéis que regresar como si no fuerais nada a empezar de nuevo, desde abajo, desde cero, en una España nueva [...] Y para ese esfuerzo ya estáis viejos", comenta uno de sus antiguos comnañeros. Ibidem. $\mathbf{v} .73$.
} 
Como resultado de esos reencuentros con la España de ayer, que lo recriminó, y con la de mañana, que lo ignoró, este español de la guerra llegó a afirmar que lo terrible no había sido el destierro sino la vuelta; porque uno siempre era el que se fue, mientras lo que dejó había seguido avanzando. El refugiado contempló entonces su exilio como un corte fundamental en su experiencia vital como individuo. El exilio fue un paréntesis en su vida que, una vez concluido, hizo imposible su reincorporación a una realidad que había avanzado de forma independiente. España tenía poco que ver con la vivida por el exiliado en el momento en que ese mundo se detuvo para él y mucho menos con la que, alimentada por la nostalgia, había recreado en su memoria. España ya no tenía nada que ver con lo que era, mientras él seguía siendo el mismo; y es que "para nosotros cada amanecer tenía un cuarto de siglo de retraso". Fuera del juego tras la vuelta, sin posibilidad ${ }^{30}$ ni fuerza para participar en un juego al que había que darse por entero, el exiliado tomó plena conciencia de algo: el paréntesis se había tornado en ruptura. Lo que empezó siendo una interrupción en su experiencia vital se había convertido en una situación crónica, un exilio permanente; el fin del exilio había demostrado que el exilio no tenía fin.

Tras años de soñar con el regreso, tras poner todas sus esperanzas en él, éste se tornó amargo cuando se dio cuenta de que el exilio y la guerra estaban ya en los libros de historia; estaban muertos. Lo suyo empezaba a tener importancia para los historiadores, afirmaba el protagonista de la historia, lo que demostraba que ya no tenían nada que hacer. $\mathrm{El}$ retornado concluye que no eran más que una legión de muertos, el sacrificio de cuantos marcharon de España había sido vano. Aún había algo peor, los exiliados no eran siquiera héroes del pasado, sino fantasmas. No eran nada, el exilio no existía en la memoria de los españoles; y si había algo peor que morir en tierra extraña era morir en el olvido.

En definitiva, muerto Franco, el exilio estaba oficialmente acabado porque se podía volver en la práctica. El problema fue que volver era reintegrarse y participar y eso era imposible porque ésta no era su España, pórque les faltaba fuerza física para hacerlo y porque los españoles no se lo permitieron. Una parte de los que regresaron aceptaron quedarse en el papel de "maestros", muy alejado de los ímpetus de su juventud. Otros prefirieron retornar al segundo exilio

\footnotetext{
${ }^{30}$ Los jóvenes españoles con los que se encuentra, a la vez que les recriminan su postura crítica respecto a España: " $i \mathrm{Si}$ no les gusta para qué volvieron?", les quitan el derecho a participar en ella. "Ustedes abandonaron, se fueron del ring y no les concedemos la revancha", p. 86.
} 
y convertirlo en una forma de vida, en un exilio vital o un exilio sin fin. Unos y otros sufrieron el "complejo de olvido" y estaban convencidos de ser los parias de la historia reciente de España.

El pueblo español, decían, siempre tuvo una gran facilidad para olvidar y no aprender de su pasado. Ésa había sido nuestra tragedia histórica y podría volver a serlo. La función de los pocos exiliados activos durante la transición fue "defender su pasado" como forma de reivindicarse y salir del olvido. Contra el olvido, el exilio había de seguir dando testimonio, como símbolo de lo que ocurrió para que no se volviese a repetir. Algunos exiliados, insignes por su encomiable persistencia, continuaron trabajando, hasta el fin de sus vidas, por recuperar el exilio, como compromiso con éste y con España:

No se trata de consignar y recusar antiguas peripecias [...] sino la justa reparación, difícil mas ineludible, del daño infligido, ello tanto en lo personal como en lo colectivo, del obligado rescate de un valioso patrimonio intelectual, cultural, moral. Y de su reinserción viva en un ámbito de creadores enlaces, que ha de coadyuvar a la conciencia -renacida, por verificarse- del pueblo español. ${ }^{31}$

Perdonar sí, pero no olvidar, fue su consigna; porque el olvido significaba reconocer que sus vidas no habían tenido sentido. Para estos hombres, la transición debió basarse en una reconciliación, fruto de una asunción mutua de culpas, no en un olvido de las mismas. Patricia Fagen señaló, con acierto, que "quizás la mayor causa de frustración de los transterrados ${ }^{32}$ había sido el hecho de que, después de dedicar tanta energía a la causa española, en la actualidad no eran ni amados ni odiados en su patria, sino simplemente olvidados". ${ }^{83}$

En honor a la verdad, pocas actuaciones se llevaron a cabo en la España de la transición para recuperar la obra del exilio. Desde el punto de vista oficial, el primer reconocimiento a su labor se produjo en 1980. El PSOE presentó en las Cortes una proposición de ley

\footnotetext{
31 Manuel Andújar, "En este siglo de exilios, el exilio español de 1939", Catálogo de la exposición El exilio español en México, op. cit., p. 19.

${ }_{32} \mathrm{El}$ concepto de transterrado, aplicado a los refugiados españoles que llegaron a México en 1939, nació de las mismas filas del exilio. Fue el filósofo José Gaos quien lo acuñó, en los años cincuenta, para describir la condición de español más que desterrado en México; trasladado de una tierra a otra del mismo universo cultural y mental que constituye el mundo hispano. Por ello, el exiliado no se sentía tal en el país que lo acogió y creaba un marco ideal para acercar entre sí México y una España que se olvidó más de América que América de ella.

${ }^{38}$ P. Fagen, op. cit., p. 198.
} 
con el fin de "reintegrar las últimas emigraciones españolas al proceso de nuestra cultura". El 23 de junio de 1980 la proposición se discutió en el Senado y recibió el apoyo de todos los grupos parlamentarios. En las intervenciones, se planteó el problema del olvido de quienes, según el senador socialista Díaz Mata, "vienen aquí a dejarse querer, pero en definitiva nadie los quiere, no se les ofrecen puestos en la universidad, ni condiciones que les permitan volver conservando el grado profesional que tienen en sus lugares de residencia" ${ }^{34}$ La política a seguir era, pues, según la propuesta aceptada: revitalizar la universidad y centros de estudios, con la aportación de los exiliados a través de intercambios culturales, defender su obra intelectual y, por medio de ellos, establecer lazos de cooperación cultural con los países de migración. Al menos de esa forma se les reconocería su sentido del exilio: la aportación cultural y su papel como protagonistas del reencuentro España-América.

Para conseguirlo se proponía: crear un centro o departamento dedicado a esa tarea; hacer un censo de los españoles dedicados a la enseñanza superior en los países de exilio; recopilar sus obras, editarlas, patrocinar conferencias, reuniones y congresos que explicasen la tarea del exilio; crear, finalmente, un programa de intercambio entre universidades españolas y americanas en torno a estos profesores exiliados y a la investigación sobre el tema. Estas propuestas fueron acogidas con entusiasmo en el exilio, aunque también con cierta suspicacia, porque parecía tratarse sólo de un reconocimiento cultural. A pesar de ello, fueron publicadas por el Ateneo Espanol en un folleto titulado Homenaje a México, como el primer reconocimiento al exilio por parte de la España de la Transición. Sin embargo, las propuestas no parecieron tener resultados positivos, al menos hasta la celebración del cincuentenario de la diáspora en 1989. Demasiado tarde. Ciertamente, en esa fecha, aumentó el número de publicaciones y se celebraron varios congresos dedicados al exilio. No obstante, se trató de un reconocimiento académico que no impidió que los exiliados continuasen quejándose de la desmemoria de la sociedad española de la transición; en lo que ellos mismos reconocían, era ya un complejo de olvido. ${ }^{35}$

\footnotetext{
${ }^{34}$ Hay que tener en cuenta que uno de los elementos que de forma más clara impedía la vuelta era la imposibilidad de restablecer la vida profesional en España en la misma categoría de la que gozaban en México. Problema que se hace evidente cuando, desde el exilio, critican la no homogeneización inmediata en España de los títulos obtenidos en aquel país, lo que afecta especialmente a los exiliados de la segunda o tercera generación.

${ }^{35}$ En uno de los congresos celebrados con este motivo en 1989, en la Universidad de Maryland, vuelven a aparecer las quejas sobre una desmemoria que ven plasmada en la negativa de Felipe González a asistir al congreso al que fue invitado, cuando en los mismos días
} 
A modo de conclusión: del fin del exilio al exilio sin fin

¿Es posible volver del exilio, o es un corte tan profundo en la experiencia vital del individuo que se convierte en una situación irreversible, porque el refugiado termina sintiéndose un exiliado permanente? ¿Es posible el fin del exilio o el exilio termina convirtiéndose habitualmente en un exilio sin fin? El exiliado ve truncada su vida en el momento de la expulsión. Desde éste, de forma consciente o inconsciente, proyecta su existencia hacia el pasado, aun cuando esté viviendo el presente o esté imaginándose el futuro. El desterrado pone todo su anhelo vital en la vuelta. No hay nada peor para un exiliado que morir en el exilio, por cuanto se frustra la única esperanza que le queda: la del retorno. No obstante, aunque lo consiguiera, la vuelta es siempre imposible. El exiliado ha sufrido un doble proceso: la sublimación de su tierra y la congelación mental de la imagen de su patria. "Sus ojos no ven lo que miran sino lo que llevan dentro" ${ }^{36}$ Eso crea un extrañamiento entre la imagen mental del exiliado y la realidad que se encuentra a la vuelta. El retorno, en el pleno sentido de reintegración que tiene la palabra, es imposible. Cuando el exiliado toma conciencia de esa imposibilidad, se da cuenta de que su exilio es una ruptura total en su experiencia vital. Ese corte traumático impide tanto la reintegración a su tierra, como la asimilación total en la que lo cobija. El exilio se convierte, entonces, en una condición vital, un exilio sin fin.

En los años setenta, muerto Franco, desde el punto de vista jurídico político, ese exilio desapareció; no ocurrió así en el plano mental. Varias disposiciones dictadas por el régimen, desde 1945 en adelante, habían abierto el proceso de recuperación del exilio para España; sin demasiada fortuna en el caso mexicano. Al exiliado se le presentó la difícil disyuntiva de volver o quedarse. Unos pocos volvieron con éxito incluyéndose en el proceso de transición política que se inició en 1975. Para la mayoría, la ilusión de volver fue unida al dolor de romper con un medio en que habían estado integrados demasiado tiempo. Gran parte del exilio no se planté la posibilidad de la vuelta más que en un sentido temporal, como cualquier emigrante económico. Volver ya no era posible, sobre todo porque habían adquirido en México un alto status social y profesio-

\footnotetext{
estaba en Washington de viaje oficial. Olvido que queda patente, además, en la concesión de] Premio Cervantes a quien estuvo "claramente comprometido con los vencedores".

${ }^{36}$ Vicente Lloréns, "Retorno del desterrado", Cuadernos Americanos, julio-agosto de 1948, p. 227.
} 
nal y venir a España significaba empezar otra vez desde cero. $Y$ a ello había que añadir un hecho fundamental: ¿volver? Sí, pero, ¿̇a dónde? Retornar a "su España", pero qué ocurría si su imagen de España no coincidía en nada con la que se encontraron al volver.

Al regresar, el exiliado se sintió perdido en la nueva España; lo que fue peor, se sintió olvidado por ella ${ }^{37}$ En cualquier caso, la valoración de ese olvido y sus consecuencias fueron distintas según la situación del exiliado que la vivió. Para quien vivía ya como un gachupín en México, ese choque no fue tan traumático; sí lo fue para los exiliados aún activos políticamente. Entre éstos se dieron distintas reacciones. La primera fue regresar a España, a pesar de todo, a luchar en la transición.

Junto a los que se incorporaron a la transición, que fueron los menos, los hubo que no lograron superar esa decepción. A éstos sólo les quedó volver a su exilio, donde el objeto de su nostalgia y añoranza no era sólo España, sino los ideales de juventud y los recuerdos de esos años, más valorados conforme se acercaba la vejez. Volver a su exilio era convertirlo en permanente, en una postura vital. Independientemente de la existencia física o jurídica del exilio, ese exiliado se sintió como tal. Se situó, entonces por decisión propia, fuera. Fuera de una España que no era la que soñó, fuera de un país de acogida en el que los recuerdos le impedían integrarse plenamente. Encerrados en ese exilio vital llegaron a pensar que eran hijos de la España exiliada, una España alternativa, desterrada continuamente a lo largo de su historia; un paraíso perdido. Ésta fue la opción más romántica, la que prefirieron los escritores refugiados, sobre todo los jóvenes poetas de la segunda generación del exilio.

Pero les quedaba otra alternativa: podían, y es ahí donde está la gran aportación del exilio mexicano, realizar plenamente la idea de la doble patria que José Gaos intuye en su concepto de transtierro.

\footnotetext{
${ }^{97}$ Ricardo Garibay en "Por aquellos españoles...", publicado en la obra colectiva El exilio español en México, op. cit., p. 96, señala la dureza del reencuentro del exiliado con su tierra. Más duro si se trataba de aquellos que fueron jóvenes a México o nacieron allí, porque ellos habían idealizado la tierra "prometida" de sus padres. Conservaban, pues, como parte de su herencia, esa imagen de España idealizada que reforzaba lo positivo y olvidaba lo negativo. Pero, en no pocas ocasiones, la segunda generación en el exilio vivía con un sentimiento de amor-odio hacia esa España idealizada y congelada de sus padres, por la cual habían visto sufrir a sus congéneres durante toda su niñez y adolescencia. Garibay recoge perfectamente los sentimientos de ese grupo al visitar España. Al llegar a la península una representante de la generación que llegó niña al exilio, Matilde Mantecón, lloró amargamente al darse cuenta de que "España, la recordada apenas, oída tantas veces, ya no existía, era un paraíso perdido irremediablemente, un paraíso al que a fin de cuentas uno nunca pudo llegar". Ese reencuentro decepcionante le demostró algo: que había nacido exiliada, ciudadana de un paraíso inexistente.
} 
Perdido el sentido político de su destierro, los exiliados se esforzaron en dar otro sentido a su situación, otra utilidad a sus vidas. Se convirtieron, por decisión propia, en los primeros ciudadanos del mundo hispanoamericano. Los protagonistas de un nuevo mestizaje cultural y biológico, a través del cual se podría hacer realidad el reencuentro de España y América. Lo consiguieron. El principal problema es que esa España que corrió un tupido velo sobre los dos bandos de la guerra civil para hacer una transición pacífica sacrificó al olvido el esfuerzo de estos hombres, para cambiar la imagen de España en México y para crear un nuevo concepto de hispanidad, aceptable para América y para España. 